a more user friendly system. When the proposed changes to the NHS begin to take effect some practices may find that under budgetary pressures staffing levels have to be rationalised. Particularly for certain urban practices, organised open access surgeries might allow redeployment of staff or practices to function with fewer receptionists without having to compromise patient care.

I thank Nicky Britten, Myfanwy Morgan, and David Armstrong of the United Medical and Dental Schools of Guy's and St Thomas's Hospitals for their critical comments; Nigel Smeeton of the Department of Public Health Medicine at the United Medical and Dental Schools of Guy's and St Thomas's Hospitals, Paul Harris of NOP Market Research Limited, Mike Cooke of Numbers, and Jeremy Coyle for their statistical help; and my wife, Christine Roberts, for help in designing the questionnaire. This paper reports findings from a research project presented in part requirement for the degree of MSc in general practice at the United Medical and Dental Schools of Guy's and St Thomas's Hospitals, University of London (1989).

I Field J. Problem of urgent consultations within an appointment system fR Coll Gen Pract 1980;30:173-7.
2 Tavlor B. Patient use of mixed appointment system in an urban practice. Br.Med f 1984;289:1277.

3 Wilkin D, Hallam L, Leavey R, Metcalfe D. Anatomy of general practice. London: Tavistock, 1987:128.

4 Mechanic D, Volkart EH. Stress, illness behaviour and the sick role. American Sociological Review 1961;26:51-8.

5 Goldberg D, Williams P. Manual of the general health questionnaire. 2 nd ed. Slouth: NFER-Nelson, 1987.

6 Corney RH. Development and use of a short self-rating instrument to screen for psychosocial disorder. I R Coll Gen Pract 1988;38:263-6.

7 Siegel S. Non-parametric statistics for the behavioural sciences. New York: McGraw-Hill, 1956

8 Corney R, Murray J. The characteristics of high and low attenders at two general practices. Society of Psychiatry and Psychiatric Epidemiology 1988; 23:45.

9 Zola IK. Pathways to the doctor: from person to patient. $S o c S_{c}$ Med 1973;7:677-89.

10 Scambler A, Scambler G, Craig D. Kinship and friendship networks and women's demand for primary care. $\mathcal{F} R$ Coll Gen Pract 1981;31:746-50.

11 Morgan M. Marital status, health, illness and service use. Soc Sci Med 1980;14A:635.

12 Bridges KW, Goldberg DP. Somatic presentation of DSM III psychiatric disorders in primary care. $f$ Psychosom Res 1985;29:563-9.

13 Murphy M. Somatisation: embodying the problem. Br Med f 1989;298:1331

14 Tylee A, Freeling P. The recognition, diagnosis, and acknowledgement of depressive disorder by general practitioners. In: Herbst KR, Paykel ES eds. Depression, an integrative approach. Oxford: Heinemann, 1989:216.

15 Balint M. The doctor, his patient and the illness. London: Pitman Medical 1957:34.

16 Locker D. Symptoms and illness. London: Tavistock, 1981:178

17 Arber S, Sawyer $L$. The role of the receptionist in general practice: a "dragon behind the desk?" Soc Sci Med 1985;20:911-2

(Accepted 2 May 1990)

\title{
Screening in Practice
}

\section{Reducing the psychological costs}

\author{
Theresa M Marteau
}

For the foreseeable future screening will be an integral and growing part of our health care system. Technical advances, particularly in biogenetics; increasing expenditure on health; and, more recently, financial incentives for general practitioners to carry out some screening are resulting in more people being screened for more conditions over greater spans of their lives. But screening may sometimes do more harm than good. The way an effective screening test is implemented will influence how much good and how much harm it does. Many people undergo screening without understanding precisely what the test is for, the accuracy of the test, and the implications of any possible test results. These are the roots of many of the potentially avoidable adverse psychological consequences of screening.

\section{What are the psychological costs of screening for patients?}

High levels of anxiety have been reported in patients participating in many screening programmes, including cervical screening, breast cancer screening, and general health screening. ${ }^{1}$ Anxiety is undesirable not just in itself but also because it can have "knock on" effects on patients' physical health, ${ }^{2}$ increasing consultation rates while reducing patients' ability to recall and act on any advice offered.

For some, simply receiving an invitation to participate in a screening programme will induce anxiety. Most of those participating in screening will receive a normal test result. Although this knowledge is usually reassuring, it does not always allay the anxieties and uncertainties raised by participation: some patients will be more anxious after screening than they were before. ${ }^{+}$Others will overgeneralise a normal result to mean a clean bill of health, and this may reinforce an unhealthy lifestyle.

Some patients who receive a normal result will subsequently be shown to have the condition being screened for. We know comparatively little about how such patients cope with the aftermath of such a false negative result. It is possible that they may experience more difficulty in coming to terms with the disease than if they had received a positive result on their first screening test.

Some patients will receive a positive test result on first testing. This news invariably causes much distress. Depending on the sensitivity of the screening test, a proportion of patients with a positive test result will subsequently be found not to have the disease. Not al patients will be reassured by this: anxieties may remain for months or even years after a false positive result.'

\section{How can these psychological costs be avoided or reduced?}

The psychological effect of participating in a screening programme is often neglected both in research and practice. Many of the undesirable psychological effects of screening can be avoided or reduced by carefu attention to patients' needs at each stage of the screening process - that is, inviting patients to participate in a screening programme, preparing those who decide to undergo the test, and giving results. Before setting up any screening programme a written protocol should be prepared. This should include details of how interactions with participants should be conducted at each of these stages.

\section{Inviting people to participate in screening}

There are two main methods of recruiting participants: by letter, and opportunistically (that is, when the health professional takes the opportunity to tell a patient about a screening test during a consultation for some other reason). To minimise anxiety, a letter should state why the patient is being invited. If it is a 
routine request, this should be stated. One study found that some women misinterpreted an invitation to attend for cervical screening as evidence that their general practitioner knew that they had cancer. ${ }^{3}$ For people to engage in health promoting actions they must perceive a risk to their own health and believe that the action being proposed will reduce that risk. The more knowledge people have about the benefits of undergoing a screening test, the more likely they are to attend. ${ }^{6}$ The letter therefore should state why this particular patient has been sent the letter, the nature of the risk, and how undergoing screening may reduce it. This information should also be given when patients are informed about a screening test opportunistically.

\section{Points to include in an invitation for screening}

- Why this particular patient has been invited

- The condition being screened for-that is, the health risk

- How participation in screening may reduce this risk

\section{Pretest preparation}

Once patients have agreed to undergo screening, many of the adverse psychological consequences of screening can be avoided or reduced if they are given detailed, accurate information in a sensitive manner before they undergo the test. The information given should include what is being tested for (and what is not being tested for), how the test will be carried out, when and how the results will be available, the likelihood of being recalled, and the meaning of the results (both positive and negative). This information is most effectively given orally by the doctor, nurse, or technician carrying out the screening test, ${ }^{7}$ and supplemented by written material. To reduce the high levels of distress among those recalled on a routine screening test it is worth emphasising, firstly, that being recalled is not unusual - for example, most women are unaware that as many as one in 10 will be recalled after a cervical smear; and, secondly, that a positive result on a first screening test is not the same as a diagnosis of the disease. Indeed, for some screening tests (such as cholesterol or hypertension) it should be clearly stated that it is vulnerability to a disease that is being assessed, not the presence or absence of disease.

\section{Information to give patients before a screening test}

- The condition being screened for

- The test procedure

- When and how test results are available

- Likelihood of a positive result

- Meaning of both negative and positive results

- Action for those with a positive result

There is currently much variation in the amount and type of information people are routinely given when they attend for a screening test. This ranges from no information at all, such as when blood is screened for some condition without the patient being aware that screening is taking place (as occurs, for example, with some neonatal screening ${ }^{8}$ ) to formalised pre-test counselling as exemplified in the recommendations for screening for HIV antibodies. Some health professionals feel that detailed information will needlessly worry patients, most of whom will receive a negative result. However, health professionals consistently underestimate the amount of information patients want. ${ }^{9}$ Moreover, although there is no evidence that giving patients detailed information about a screening test raises their anxiety levels, there is some evidence that information can reduce anxiety in those who are recalled. ${ }^{10}$

\section{Giving the results}

WHAT RESULTS TO GIVE?

Both negative and positive results should be relayed to patients. Being told to assume that no news is good news is not as reassuring to patients as being told that their test results are negative. ${ }^{11}$ Many hospitals running maternal serum $\alpha$ fetoprotein screening in antenatal clinics to detect open neural tube defects do not routinely inform women if the results are negative. Despite a firm recommendation that women undergoing cervical screening should receive their test results, about one third of district health authorities still do not routinely inform women if the result of their test is negative.

\section{HOW TO GIVE RESULTS}

Negative results may be given over the telephone, but it is important to confirm by letter. This is also an

\section{Key points in running a screening programme}

- Prepare a written protocol covering all aspects of screening

- Train staff

- Issue motivating-not threatening-invitations and reminders

- Give information orally and in writing before the test

- Inform all patients of their test results

- Follow up all patients with positive results

- Evaluate both epidemiological and psychological outcomes of the programme

opportunity to reiterate what a negative result means. For screening tests that assess changeable risks-such as screening for coronary heart disease, breast cancer, and cervical cancer - the letter could include advice on how patients can maintain their low risk state. For example, after receiving a cholesterol result in the desired range, patients could be told what food they should eat to increase the chances that their cholesterol levels stay low. For patients receiving a negative smear result, they could be told of the advantages for cervical health of not smoking and using barrier forms of contraception.

Positive results will be relayed to patients in a variety of ways: by telephone, by post, during a prearranged appointment, or by an unscheduled home visit. If patients are being informed by telephone or by post they should be offered the earliest opportunity (within 24 hours) to discuss their result with a doctor who is fully cognisant of the screening test. It is not acceptable to inform a patient of a positive result by telephone on a Friday afternoon without offering a consultation before the Monday. Patients will not always voice their concerns to health professionals. All patients will have some concerns on receiving a positive result; some patients will receive such news as a real threat to their life. It is incumbent on those running screening programmes to offer to see all patients who receive 
a positive result; if anxieties continue, referral for counselling should be considered.

The impact of a positive test result will in part depend on how this news and its implications are conveyed and on the form that follow up takes. For example, the negative effect of learning that one is a carrier for a recessive genetic disease, such as cystic fibrosis or Tay-Sachs disease, may be lessened by reiterating that this has no implications for the carrier's own health. Providing patients who have raised blood pressure on first screening with a reassuring message rather than the traditional message portraying blood pressure as a silent killer can reduce both anxiety and the prevalence of sustained hypertension. ${ }^{12}$ Patients who receive an abnormal smear result are less anxious if they are given information about the implications of this, in particular that it is highly unlikely that they have cancer. ${ }^{10}$

\section{Staff training}

Staff training is the cornerstone of successful screening programmes. Yet this is one of the more neglected aspects of running screening programmes.

For staff to run a successful screening programme, they must first of all be fully informed themselves about the screening test they are offering. They will need to be trained in how to present information so as to ensure that patients understand the test and its implications and that their concerns and anxieties are addressed. Staff also need to be trained in how to give test results, particularly positive results, and where appropriate how to encourage patients to change their behaviour to reduce their risks of illness. Many health professionals assume that they already have these skills, but evidence suggests that a brief training course for all those who participate in running screening programmes will reap benefits. ${ }^{13}$ For health professionals in teaching districts such training can be set up in conjunction with those who teach communication skills in the hospital and medical school. In nonteaching districts help may be obtained from the district based health education officers or psychology department.

\section{Conclusion}

All new screening programmes should include evaluation of the psychological impact of invitation and participation. Audit of screening services should include assessment of measures taken to reduce the psychological costs. Such measures could, for example, include standardised assessments of patients' understanding of the test and assessments of anxiety. Only in this way will we know whether attempts to minimise the distress now known to be associated with screening are successful, and whether the benefits of a screening programme outweigh its costs. Small modifications to the way screening programmes are carried out can have large benefits both for individual patients and for the overall effectiveness and efficiency of the health care system. Attention to the psychological aspects of screening programmes (and indeed of most other health care) will yield such benefits.

1 Marteau TM. Psychological costs of screening. Br Med f 1989;299:527.

2 Totman R. Mind, stress and health. London: Souvenir Press, 1990.

3 Nathoo V. Investigation of non-responders at a cervical cancer screening clinic in Manchester. Br Med F 1988;296:1041-2.

4 Stoate HG. Can health screening damage your health? $f R$ Coll Gen Pract 1989;39:193-5.

5 Tymstra T, Bieleman B. The psychosocial impact of mass screening for cardiovascular risk factors. Fam Pract 1987;4: 287-90.

6 Norman P, Fitter $M$. Intention to attend a health screening appointment: some implications for general practice. Counselling Psychologv Quarterly 1989;2: $261-72$

7 Leigh JM, Walker J, Janaganathan P. Effects of a preoperative anaesthetic visit on anxiety. $\mathrm{Br}$ Med $\mathcal{F} 1977$;ii:987-9.

8 Smith RA, Williams DK, Sibert JR, Harper PS. Atritudes of mothers to neonatal screening for Duchenne muscular dystrophy. Br Med $\mathcal{F}$ 1990;300. 1112 .

9 Marteau TM. Ethics of clinical research. Br.Med f 1989;299:513-4

10 Wilkinson $\mathrm{C}$, Jones JM, McBride J. Anxiety caused by abnormal result of Wilkinson C, Jones JM, McBride J. Anxiety caused by abno
cervical smear test: a controlled trial. Br Med f 1990;300:440.

11 Robinson JO, Hibbard BM, Laurence KM. Anxiety during a crisis: emotional effects of screening for neural tube defects. $\mathcal{F}$ Psychosom Res 1984;28:163-9. 12 Rudd P, Price MG, Graham LE, et al. Consequences of worksite hypertension screening. Am f Med 1986;80:853-60.

13 Bird J, Lindley P. Interviewing skill: the effects of ultrabrief training for general practitioners. A preliminary report. Med Educ 1979;13: $349-55$

\section{MULTICULTURAL MEDICINE}

\section{Nowt so queer as folks}

This multicultural medicine is a complicated business. After 21 years in this practice I am just beginning to understand the local immigrant community, but it can still astonish me.

A patient brought in his newly wedded bride to register. She had arrived six weeks previously to be married and now thought she might be pregnant. She spoke not one word of English. I put her up on the couch as a gesture as I did not expect that anything would be palpable per abdo. I was surprised to find something palpable well above the pubis. Knowing her community's strict morality I was unwilling to believe it was a pregnancy and thought of tumours. A scan would reveal all. It did: a normal 20 week pregnancy.

I had recently been writing letters to officials in the Middle East, pleading for mercy for a young woman under penalty of death. She had come as an au pair in the family of a rich oil magnate and had become pregnant, probably by the father of the family she was working for. She had been found guilty of adultery and condemned to be stoned to death after the baby was born. A vigorous international campaign succeeded in getting the sentence commuted to flogging and, after renewed efforts, reduced to repatriation.

With this hideous story in my mind, I contemplated the young woman before me. There was no way the baby could be her husband's; when it was conceived he and she had been living in different continents. I had visions of my patients being divorced, flown home, and sentenced to unthinkable punishment. Her country was not in the Middle East, but it was an Islamic state with strict Islamic laws. I could not communicate with the patient except through her husband. There was only one course of action: keep my mouth shut and use a little masterly inactivity. I told the husband, truthfully, that his wife was pregnant and all was well, and to come again in a month. I made a note to warn the consultant at the antenatal clinic.

A month later they returned for a routine check up. Fundus, 24 weeks, movements felt by the mother, all well. I wrote out a prescription for iron and folic acid, handed it to the husband, and said, "Come back in another month." He did not move. "Er-Doctor?" "Yes?" "Do you think-I mean, is it possible that, er, she might be-you know-a bit more than three months?"

Oh God, he's cottoned on. I glanced at the mother and was reassured to see her giggling. "Weeell. . . ." "Because, you know, Doctor, three months before we were married I went for a holiday back home, to visit her, you know, and we. ..."

I was speechless, and then relief made me burst out laughing. "Why on earth didn't you tell me at first?" I managed to say at last. He grinned sheepishly. "We didn't like . . . we thought you might be, you know, offended.”-ANN LENTHALL, „ general practitioner

$\star$ This is not the doctor's real name. 